\title{
Understanding eating behaviours in Spanish women enrolled in a weight-loss treatment
}

\author{
Ana Maria Barberia MSc, MPhil, RGN \\ MPhil Student, School of Nursing Midwifery \& Social Work, University of Manchester, Manchester, UK \\ Moira Attree MSc, PhD, RGN \\ Lecturer, School of Nursing Midwifery \& Social Work, University of Manchester, Manchester, UK
}

Christopher Todd BA, MA, PhD

Professor of Primary Care \& Community Health, Director of Research, School of Nursing Midwifery \& Social Work, University of Manchester, Manchester, UK

Submitted for publication: 27 September 2006

Accepted for publication: 3 May 2007

\section{Correspondence:}

c/o Moira Attree

School of Nursing Midwifery \& Social Work

Coupland 3 Building

University of Manchester

Oxford Road

Manchester M13 9PL

UK

E-mail: moira.attree@manchester.ac.uk
BARBERIA AM, ATTREE M \& TODD C (2008) Journal of Clinical Nursing 17, 957-966

Understanding eating behaviours in Spanish women enrolled in a weight-loss treatment

Aim. To identify the beliefs and attitudes of a sample of obese and overweight Spanish women undertaking a weight-loss treatment.

Background. Obesity is a global epidemic. Weight-loss treatments focus on changing eating behaviours; however, many patients fail to adhere to the diet. This suggests that more effective behaviour-change interventions are required to help people change their eating behaviours. According to the theory of planned behaviour (TPB) human behaviour is influenced by beliefs. Identification of people's beliefs is an essential step in the design of behaviour-change interventions.

Design. A qualitative approach was employed using semi-structured interviews to interview participants. Seventeen obese and overweight Spanish women enrolled in a weight-loss treatment were recruited using a criterion sample strategy.

Findings. Participants' reported beliefs referring to the benefits of losing weight and the emotions related to dieting. The more positive these beliefs were the more positive their attitude towards the diet seemed to be. Findings highlight the importance of follow-ups in creating a subjective norm to maintain a diet. Perceived behavioural control to diet seemed to be related to beliefs about social support; whereas beliefs about lack of willpower to overcome temptations seemed to decrease perceived control over eating behaviours.

Conclusions. Participants reported several beliefs and attitudes that offer plausible explanations of their eating behaviours. Data from this study seemed to fit the propositions of the TPB and could be used in further research to develop effective eating behaviour-change interventions.

Relevance to clinical practice. Nurses could use the TPB to assess individuals' attitudes, beliefs and expectations when following a diet. That assessment would provide 
insight into what aspects are relevant for individual patients when dieting, which could lead to more effective diet behaviour-change interventions being designed.

Key words: attitudes, beliefs, behaviour, nurses, nursing, obesity

\section{Introduction}

Obesity constitutes the most common metabolic disease in developed countries; the World Health Organization (2002) describes obesity as a 'global epidemic'. In Spain, the prevalence of obesity increased from $9 \cdot 7 \%$ in 1999 to $13.3 \%$ in 2003 (Spanish Department of Health 2003). Similar trends are evident in America and the United Kingdom. In 1991 only four American states had an obesity prevalence higher than $15 \%$; whereas in 2005, 20\% of the American population was obese (Centers for Disease Control and Prevention 2006). In England, the prevalence of obesity in men and women increased from $13.2 \%$ and $16.4 \%$ respectively in 1993 , to $23.6 \%$ and $23.8 \%$ in 2004 (Department of Health 2005).

Obesity is a major public health concern as it contributes to significant excess disease and mortality (National Heart Lung and Blood Institute NHLBI 1998); increasing the risk of hypertension, diabetes, cardiovascular disease and cancers (American Obesity Association 2002). In Spain the increasing prevalence of obesity is accompanied by rising frequency of these conditions (Spanish Department of Health 2003).

Among the factors related to excess weight, two stand out as being modifiable: excessive calorie intake and sedentary lifestyle. Weight-loss management aims to change patients' eating and exercise behaviours (NHLBI 1998). However, many patients fail to adhere to diet and exercise programmes (NHLBI 1998).

\section{Background}

Most behaviour change interventions attempt to modify cognitions as these are more amenable to change than other factors (i.e., culture, gender) (Conner \& Norman 1996b). There are no published studies exploring cognitive factors associated with eating behaviours of Spanish people following a diet. This gap is important as understanding of these factors can help health professionals to develop more effective behaviour change interventions that would help obese people modify their eating behaviours and lose weight.

\section{The theory of planned behaviour}

The theory of planned behaviour (TPB) (Ajzen 1991) is a theoretical approach that has been used to develop behaviour change interventions targeting cognitive factors. Its central factor is intention, which is a function of attitudes, subjective norms and perceived behavioural control (PBC) (Fig. 1). Attitude depends on behavioural beliefs and on the evaluation of those outcomes. Subjective norms are influenced by normative beliefs and by the individual's motivation to comply with these expectations. Finally, PBC depends on control beliefs and the perceived power of each factor. PBC can have a direct impact on behaviour when the individual does not have total control of the behaviour. Therefore, the TPB allows prediction of behaviour that is not completely under volitional control (Ajzen 1991). Changing or introducing new beliefs would result in a more favourable attitude and subjective norms and in a greater perceived control to perform it. Changes in those determinants would result in stronger intentions to engage in that particular behaviour and consequently, the individual would be more likely to perform it (Ajzen 1991).

Meta-analytic reviews of the TPB conclude that it provides a good model to understand and predict intention and health behaviour (Godin \& Kok 1996). This is consistent with Ajzen's (1991) review and compares favourably with results

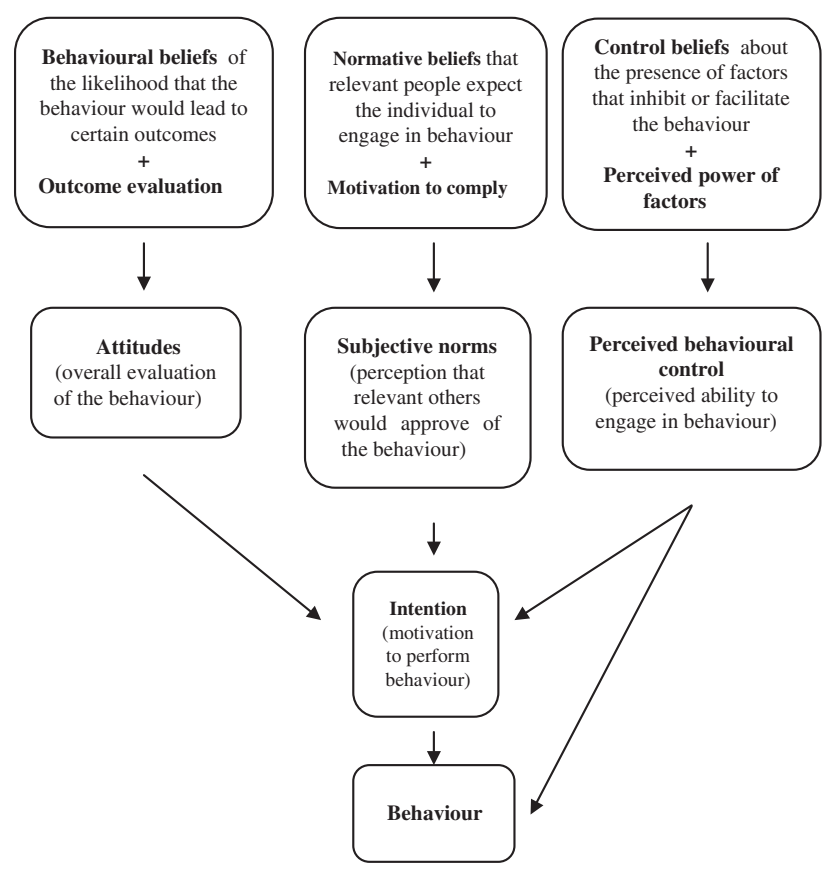

Figure 1 The theory of planned behaviour (Ajzen 1991). 
from later studies that show that attitude, subjective norms and $\mathrm{PBC}$ are associated with intention and that behaviour is influenced by intention and PBC (Blue 1995, Hausenblas et al. 1997, Conner \& Armitage 1998, Armitage \& Conner 2001, Hagger et al. 2002). Moreover, the correlations between behavioural, normative and control beliefs with attitude, subjective norms and $\mathrm{PBC}$ represent medium to large effect sizes. These determinants are associated with intention and behaviour, including eating behaviours (Ajzen 1991, Armitage \& Conner 1999, 2001, Godin \& Kok 1996, Povey et al. 2000).

As a social cognitive model (SCM) the TPB receives similar criticisms. SCMs only account for a small amount of variance in behaviours (Norman \& Conner 1996, Sutton 1998). Possible explanations are that there were methodological problems with measurements and operationalization of the determinants and behaviour, or that new variables may need to be added to SCMs (Norman \& Conner 1996). Consequently, the TPB has re-defined the conceptualization of its variables to achieve a better understanding of behaviours (Ajzen 2002a). In addition, the TPB includes normative influences, which are not included explicitly by other SCMs and other variables that allow the theory to be used in preventive health interventions (Norman \& Conner 1996, Armitage \& Conner 2000, Hardeman et al. 2002). Armitage and Conner (2000) and Hardeman et al. (2002) argue that the TPB constitutes an improvement on other SCMs.

The TPB has some important strengths that make it potentially effective in the development of behavioural interventions. It offers a small but sufficient number of modifiable determinants of behaviour that can be used as theoretical background to explore individual's behaviour (Conner \& Norman 1996c). Its grounding approach, to elicit salient beliefs of the population of interest, allows researchers to identify individual and cultural differences that may affect behaviour (Young et al. 1991).

Many studies have used the TPB to understand different eating behaviours (i.e. vegetarian diets or fat intake) among different populations (Nguyen et al. 1996, Anderson et al. 1998, Paisley \& Sparks 1998, Armitage \& Conner 1999, Berg et al. 2000, Povey et al. 2000, 2001, Malasu \& Astrom 2001, Conner et al. 2002). However, none were carried out with obese and overweight people in Spain. This is important as the TPB highlights that the same attitudes and beliefs may not exist for different behaviours, or for the same behaviours across different populations. Consequently, the TPB is operationalized into a series of discrete steps when developing an intervention (Ajzen 1991) (see Table 1). On the basis of this understanding of the relative importance of specific components of
Table 1 Steps to develop a theory of planned behaviour (TPB) intervention (Ajzen 1991)

Steps to develop a TPB intervention

1 Define the target behaviours and target population, as it cannot be assumed that the same drivers exist for different behaviours, or for the same behaviours across different populations.

2 Identify model salient beliefs regarding a particular behaviour in the target population using qualitative methods.

3 Construct a questionnaire to assess these beliefs, as well as the relative contribution that attitude, subjective norms, perceived behavioural control and intention have on the behaviour in question in the target population.

4 Explore differences in beliefs between intenders and non-intenders to perform the targeted behaviour.

5 Decide which interventions are more adequate to change those beliefs.

attitudes, subjective norms and $\mathrm{PBC}$ an intervention can be designed aimed at changing intentions and behaviours (Ajzen 1991).

\section{The study}

\section{Aims}

We aimed to generate knowledge that would inform the development of effective future eating behaviour-change interventions to help obese and overweight women follow a diet and lose weight. The objectives were to:

- Elicit the salient behavioural, normative and PBC beliefs that obese and overweight Spanish women hold towards eating behaviours;

- Explore qualitatively the relationship between these beliefs and attitudes, subjective norms and PBC.

\section{Design}

The study adopted a qualitative approach using grounded theory principles (Glaser \& Strauss 1968), to generate and explore the beliefs and attitudes underlying Spanish women's diet behaviours. The beliefs and attitudes generated from participants were then compared with the constructs and propositions of Ajzen's (1991) TPB. It was envisaged that the study findings could be used to complete the steps that Ajzen (1991) proposed for the design of future behaviour-change interventions for the target population (Table 1).

\section{Participants}

Our target population was female patients following a weight-loss treatment in an outpatient clinic in a private 
hospital in Spain. The treatment includes nutritional education provided by a nurse or dietician and an individual diet based on the patient's medical history and previous eating behaviours. Patients are also advised to exercise. In some cases, this therapy is complemented with pharmacological treatment. Each patient is followed up every 3 or 6 months.

Participants were selected using criterion sampling (Patton 2002), which involved inviting all obese (Body Mass Index (BMI) $>29.9 \mathrm{~kg} / \mathrm{m}^{2}$ ) and overweight $\left(\right.$ BMI $\left.=25-29 \cdot 9 \mathrm{~kg} / \mathrm{m}^{2}\right)$ female patients, over 18 years old, attending the clinic for a conventional weight-loss treatment (diet and exercise) to participate in the study $(n=29)$. The rationale for using a criterion sampling strategy is that it would allow us to obtain a diverse range of participants who would express a broad picture of the most frequent beliefs held by the target population (obese and overweight women following a diet and exercise therapy to lose weight at that hospital in Spain) (Patton 2002). Patients receiving pharmacological or surgical treatment for weight loss, those diagnosed with a binge eating disorder were excluded, as were patients treated or scheduled to be treated to lose weight prior to impending surgical intervention. Males were not included in the study as the number of males attending the clinic was very small.

Patient recruitment commenced in September and ended in December 2003, when no new information emerged from interviews (data saturation) (Glaser \& Strauss 1968). Data saturation determined the size of the sample. Two doctors, the nurse and dietician in charge of the weight-loss treatment invited patients who met the inclusion criteria to participate in the study. However, they failed to invite three patients. Therefore, of the 29 females that were seen by the health team in that period, only 26 were invited to participate in the study and 24 agreed. Seventeen patients were interviewed before data reached saturation; at which point participant interviews ceased.

\section{Data collection}

As Godin and Kok (1996) propose, this study used semi-structured individual interviews with open-ended, non-leading questions to collect data. These enabled the researcher to access participants' descriptions of their eating attitudes and behaviour. Interviews followed a broad agenda of questions generated from the literature; these were not necessarily asked in the same order in each interview. Questions were accompanied by probes to access fuller accounts from participants. Interviews took place in various private rooms in the clinic. Interviews lasted for 30-60 minutes and were audio taped, with permission from participants. Interviews were conducted in Spanish by a native Spanish speaker $(\mathrm{AB})$, a nurse who was not part of the health team involved in the weight-loss treatment at the clinic. Data analysis was conducted on the Spanish language transcripts; illustrative quotations are translated to English for presentation in this paper.

Data collection and analysis took place concurrently; a process that allowed the researcher to modify interview questions to collect better quality data (Glaser \& Strauss 1968, Miles \& Huberman 1994).

\section{Validity and reliability/rigour}

Emerging findings were confirmed throughout data analysis. The researcher used a reflexive process to assess the way she and the research procedure might have shaped findings and interpretations of data (Miles \& Huberman 1994). The reliability of findings was checked by comparing the researchers' coding and analysis with two Spanish colleagues with experience in research, who analysed randomly selected interviews and challenged some of the researcher's initial findings (Berg 2001).

Researchers aimed to enhance the validity of the findings by seeking deviant cases (i.e., people able to follow a weightloss treatment without problems and those who found it extremely difficult). The validity of the findings was corroborated by two study participants, who recognized them as reflections of their experiences (Miles \& Huberman 1994). Acknowledging that other patients may have different perspectives on dieting (Neuman 2000), findings were also presented to the staff nurse responsible for patients' treatment (Miles \& Huberman 1994) who thought that the findings offered an accurate picture of the experiences many other patients express.

\section{Ethical considerations}

The Ethical Committee at the hospital where the study took place and the Research Ethics Committee of the University of Manchester approved the study. Health professionals treating the patients provided verbal and written information about the study and invited patients to participate. Patients interested in participating were introduced to the researcher and gave written consent to participate. In this paper, the names of the participants have been changed to ensure confidentiality.

\section{Data analysis}

Individual interviews were transcribed verbatim and analysed inductively, using a process similar to the constant 
comparison principle of grounded theory (Glaser \& Strauss 1968). The rationale for this inductive and comparative process was to avoid forcing participants' responses into predetermined categories (Glaser \& Strauss 1968) and to see whether new categories of determinants of behaviour would arise from the data, in addition to those identified in the TPB.

Themes from participants' accounts were classified into a list of codes. An initial set of categories was created by identifying connections between the codes. Codes and categories were constantly compared with each other, to identify patterns of convergence or divergence between the accounts (Glaser \& Strauss 1968). This allowed the researcher to clarify themes in further interviews and amend categories to reach a more comprehensive understanding of the topic being studied. The categories of determinants grounded in the data were then compared with the TPB.

\section{Findings}

\section{Participants}

The characteristics of the 17 participants are summarized in Table 2. Seven participants were obese and 10 were overweight. No significant differences were found between obese and overweight participants in the variables collected (Table 2). Obese and overweight non-participants were also similar to each other (Table 3). Participants are similar to non-participants in terms of age (Mann-Whitney $U=58.00$, $p=0.053)$, place of residency ( $p=0.06$, Fisher's-exact test) and marital status ( $p=1$, Fisher's-exact test) (Martinez Gonzalez 1997).

There were no significant differences in the percentage of obese and overweight people among participants and nonparticipants ( $p=0 \cdot 13$, Fisher's-exact test). However, the ratio of obese:overweight is 7:10 for participants and 3:1 for non-participants. Nonetheless, findings suggest that participants' BMI does not affect beliefs towards dieting.

\section{Main findings}

The main study findings are the beliefs and attitudes of a group of obese and overweight Spanish women under weight-loss treatment. No differences were discovered between the views expressed by obese and overweight women. Neither was any difference found between different age and socio-economic status groups. However, having to cook and being a participant who reported that they enjoyed/loved eating made a difference in beliefs towards
Table 2 Characteristics of participants $(n=17)$

\begin{tabular}{|c|c|c|c|c|}
\hline & $\begin{array}{l}\text { Total } \\
(n=17)\end{array}$ & $\begin{array}{l}\text { Obese* } \\
(n=7)\end{array}$ & $\begin{array}{l}\text { Overweight }^{\dagger} \\
(n=10)\end{array}$ & $\begin{array}{l}\text { Comparing } \\
\text { obese and } \\
\text { overweight } \\
\text { ( } p \text {-value) }\end{array}$ \\
\hline Mean age $(95 \% \mathrm{CI})$ & $\begin{array}{l}41 \\
(34-48)\end{array}$ & $\begin{array}{l}40 \\
(29-51)\end{array}$ & $\begin{array}{l}41 \\
(32-51)\end{array}$ & $0 \cdot 87^{\S}$ \\
\hline \multicolumn{5}{|l|}{ Ethnicity } \\
\hline White from Spain & 17 & 7 & 10 & NA \\
\hline \multicolumn{5}{|l|}{ Residence } \\
\hline $\begin{array}{l}\text { Living in the same } \\
\text { city where the } \\
\text { clinic is }\end{array}$ & 11 & 4 & 7 & $0 \cdot 6$ \\
\hline $\begin{array}{l}\text { Living in a } \\
\text { different city }\end{array}$ & 6 & 3 & 3 & \\
\hline \multicolumn{5}{|l|}{ Marital Status } \\
\hline Single & 5 & 1 & 4 & $0.423^{\oplus}$ \\
\hline Married & 11 & 6 & 5 & \\
\hline Widowed & 1 & 0 & 1 & \\
\hline \multicolumn{5}{|l|}{ Children at home } \\
\hline Yes & 8 & 3 & 5 & $1^{\oplus}$ \\
\hline No & 9 & 4 & 5 & \\
\hline \multicolumn{5}{|l|}{ Education level } \\
\hline Basic & 1 & 0 & 1 & $0.95 *$ \\
\hline Secondary school & 1 & 0 & 1 & \\
\hline Technical school & 2 & 1 & 1 & \\
\hline University & 13 & 5 & 8 & \\
\hline \multicolumn{5}{|c|}{ Socio-economic status (NS-SEC) $)^{\ddagger}$} \\
\hline Class 1 & 4 & 1 & 3 & $0 \cdot 61 *$ \\
\hline Class 2 & 6 & 2 & 4 & \\
\hline Class 3 & 1 & 1 & 0 & \\
\hline Class 4 & 0 & 0 & 0 & \\
\hline Class 5 & 2 & 1 & 1 & \\
\hline Class 6 & 0 & 0 & 0 & \\
\hline Class 7 & 3 & 2 & 1 & \\
\hline Class 8 & 0 & 0 & 0 & \\
\hline Students & 1 & 0 & 1 & \\
\hline Previous diets & 17 & 7 & 10 & NA \\
\hline \multicolumn{5}{|c|}{$\begin{array}{l}\text { Length of time participant has been following diet when } \\
\text { interviewed }\end{array}$} \\
\hline Up to 1 month & 11 & 5 & 6 & $1^{\bullet}$ \\
\hline $\begin{array}{l}\text { More than } \\
1 \text { month }\end{array}$ & 6 & 2 & 4 & \\
\hline
\end{tabular}

*Obese: body mass index (BMI) value $>29 \cdot 9$.

${ }^{\dagger}$ Overweight: BMI value 25-29.9 (overweight).

*(NS-SEC). Socio-economic data collected from participants in this study are adapted to the UK National Statistics Socio-economic Classification (http://www.statistics.gov.uk).

${ }^{\$}$ Mann-Whitney U-test (Martinez Gonzalez 1997).

'Fisher's-exact test (Martinez Gonzalez 1997).

**Chi-squared test for trend (Martinez Gonzalez 1997).

dieting. These findings suggest that it is essential to uncover the cognitive components that are likely to influence individuals' eating behaviours and to tailor any intervention to specifically to their needs. 


\begin{tabular}{lllll}
\hline & $\begin{array}{l}\text { Total } \\
(n=12)\end{array}$ & $\begin{array}{l}\text { Obese* } \\
(n=9)\end{array}$ & $\begin{array}{l}\text { Overweight } \\
(n=3)\end{array}$ & $\begin{array}{l}\text { Comparing obese } \\
\text { and overweight } \\
(p \text {-value })\end{array}$ \\
\hline $\begin{array}{l}50 \cdot 2 \\
(43 \cdot 0-57 \cdot 2)\end{array}$ & $\begin{array}{c}51 \cdot 3 \\
(42 \cdot 3-60 \cdot 3)\end{array}$ & $\begin{array}{c}46 \cdot 6 \\
(19 \cdot 9-73 \cdot 5)\end{array}$ & $0 \cdot 60^{\ddagger}$ \\
$\begin{array}{l}\text { Ethnicity } \\
\text { White from Spain }\end{array}$ & 12 & 9 & 3 & $\mathrm{NA}$ \\
$\begin{array}{l}\text { Marital Status } \\
\text { Single }\end{array}$ & 4 & 4 & 0 & $0 \cdot 4^{\S}$ \\
$\begin{array}{l}\text { Married } \\
\text { Widowed }\end{array}$ & 8 & 5 & 3 & \\
$\begin{array}{l}\text { Residence } \\
\text { Living in the same } \\
\text { city where the clinic is }\end{array}$ & 0 & 0 & 0 & 1 \\
Living in a different city & 9 & 2 & 1 & \\
\hline
\end{tabular}

Table 3 Characteristics of non-participants

*Obese: body mass index (BMI) value $>29.9$.

† Overweight: BMI value 25-29.9.

'Mann-Whitney U-test (Martinez Gonzalez 1997).

${ }^{\$}$ Fisher's-exact test (Martinez Gonzalez 1997).

The TPB emphasizes the importance of identifying which components are actively driving behaviours, or at least talked about as driving intentions (Ajzen 1991). Findings from this analysis compare favourably with the TPB categories of beliefs (behavioural, normative and control). Consequently, for the purposes of clarity, study findings are presented in terms of the constructs of the TPB.

\section{Behavioural beliefs and their relationship with attitudes towards dieting}

Data analysis revealed two types of behavioural beliefs that compare with what Ajzen (2002a), in a later version of the TPB, calls 'instrumental and affective beliefs'. Instrumental beliefs refer to the value that people give to a behaviour (i.e., beneficial). Affective beliefs denote experiential quality towards a behaviour (i.e., pleasant) (Ajzen 2002a). Participants expressed beliefs that dieting would make them lose weight (instrumental belief). That is a very positively evaluated and expected outcome that would improve participants' health and/or their physical appearance:

There are two reasons for me to follow a diet: my health and my physical appearance (Ana, Obese, 31 years)

I want to lose weight because I feel better with less kilograms, less tired and well...physically I would look nicer (Gemma, Overweight, 39 years)

Data analysis appears to support the TPB assumption that the positive or negative attitude given to a behaviour is influenced by people's evaluation of the outcomes that behaviour is likely to bring. The belief that the diet would make participants lose weight was related to a positive attitude towards the diet. However, some participants also reported negative affective beliefs towards the diet, which negatively affected their attitude towards it:

It is a pleasure lying on the sofa, reading the newspaper or watching a movie while eating a pizza... Do you follow me? When you see your vegetables there...it is not that I don't like them, but there are times when you feel like enjoying your food...eating a fried egg... (Sonia, Obese, 35 years)

Data suggest that affective beliefs are more problematic and played a powerful role for the four participants who reported that they enjoy/love eating.

\section{Normative beliefs and their relationship with subjective norms}

Analysis shows that normative beliefs identified in the data can be divided into what, in new developments of the TPB (Ajzen 2002a), are called injunctive and descriptive norms. Injunctive norms refer to the perception of approval or disapproval of a behaviour; whereas descriptive norms refer to perceptions of others performing the behaviour (Ajzen 2002a).

Ten participants said that relatives and friends want them to diet for health reasons. Others said that their mothers and society put pressure on them to conform to the norm of slimness that society dictates (injunctive norms):

My sister-in-law is a doctor and she wants me to lose weight. She doesn't care about my physical appearance, she cares about my health, so, indirectly, she influences me. (...) My mum and me have had loads 
of arguments regarding my weight. She says that I am going to spend the best years of my life looking fat! (Ana, Obese, 31 years)

Society motivates us to look after ourselves, to be our age but with less kilograms! Yes all women of my generation try it (Emma, Overweight, 58 years)

In addition, three participants were aware that people around them were on a diet, which could be interpreted as an additional pressure to diet (descriptive norms):

Now all the girls are obsessed with diets and even when they are not overweight they ask for a diet coke and things like that (Carmen, Overweight, 23 years)

Initially participants appeared to want to start a diet because they had internalized these perceived pressures and accepted the subjective norm to follow a diet:

As I told you, I am vain, coquette and now I don't like the way I look, so I want to be fine! (Paula, Overweight, 61 years)

It is annoying that all the clothes in the shops are small for me, thinking that I am young and that I should be able to wear them! I know that I can go to certain shops, but it makes me angry. I am not going to wear grandma's clothes, clothes for old ladies (Sonia, Overweight, 35 years)

However, later this external pressure appeared to give way to pressure from health professionals who monitor patients' weight loss. Participants' compliance with the diet seemed to be related to a subjective norm to comply with healthcare professionals' expectations:

If a doctor follows me up I maintain the diet. When I do diets alone my problem is that I don't have self-discipline to do things, I start a diet and in five days I give up because I don't have selfdiscipline, however, if I have to come back to the person who is monitoring me, then I follow the diet. (...) I feel embarrassed if I am not doing what I am supposed to do (Maria, Obese, 44 years)

\section{Control beliefs and their relationship with $\mathrm{PBC}$}

Participants' control beliefs included beliefs about barriers and facilitators in following a diet and can be external and internal. These beliefs seemed to create perceptions about the difficulty of following the diet. In addition, participants mentioned aspects about the control that they have their overeating behaviours. These findings fit with the later version of the TPB (Ajzen 2002b), which suggests that PBC consists of two components: self-efficacy and controllability. Self-efficacy takes into account perceptions of capability to perform a behaviour and controllability refers to people's beliefs that they have control over the behaviour (Ajzen 2002a).
The most frequently reported barriers to follow a diet were lack of willpower and having to cook. Other barriers include: hunger, as well as difficulty changing their 'use' of food (i.e., food as a pleasure, a reward, as tension-reducing).

Participants who reported that they enjoyed/love eating, including the one who described herself as an 'emotional eater', tended to perceive more barriers to following a diet. These barriers were more likely to be internal (i.e., lack of willpower or difficulty in changing their use of food), than external barriers (i.e., lack of time to cook), which were more common among those who did not report enjoying eating:

I don't have problems with stopping myself from eating to follow the diet, because I am not a great eater. I have never been that keen on eating (Gemma, Overweight, 39 years)

I love cooking and I really enjoy what I cook. If I didn't see the food when I put it on the table for my children... They are always the first to have lunch and if I am starving...I always nibble a bit (Lucia, Overweight, 40 years)

When I get depressed I feel anxious and I go directly to the fridge(...)my way of escape is the food (Alicia, Obese, 27 years)

I love food(...)I don't go out as I have small children at home and the only treat that my husband and me have is food. Food is our small prize (Ana, Obese, 31 years)

The most common external barrier to following a diet is cooking, for two reasons: temptations and lack of time. Interestingly, marital status or number of children at home did not make a difference in perceptions of this barrier.

It is very hard if I have to cook for my children. Say that I am preparing 3 sandwiches of Nutella, come on! You have to have loads of willpower! And you always try a bit... (Lucia, Overweight, 40 years)

I do not cook because I don't have time, so for me it is very helpful to arrive home and have the meal cooked; that is very important when you are following a diet... My flatmate prepares the meals and that is helping me loads. Everything is thanks to her (Sandra, Overweight, 47 years)

It appears that the perception of these barriers decreases the perceived control that participants have over their eating behaviour. Nonetheless, participants expressed that they feel more able to follow a diet when they have external facilitators, such as social support.

It is much easier when my husband and me are on a diet (Marta, Obese, 32 years)

At home I eat with my parents... They are with me. They are kind of following the same diet to help me (Beatriz, Overweight, 26 years) 
Social support appeared to help patients overcome temptations as well as other external barriers, such as lack of time to cook a healthy meal.

Salient behavioural, subjective and control beliefs elicited from participants pose some interesting challenges for researchers, health professionals and patients alike, which will be discussed in the next section.

\section{Discussion}

To our knowledge, this is the first study that has explored beliefs and socio-cognitive factors in a group of obese and overweight Spanish women under weight-loss treatment. However, readers should approach our findings with some caution. Only white Spanish female participants from one clinic, who intended to follow a diet and attended follow-up appointments, were included; beliefs and motivations of non-intenders may be different from intenders. The beliefs of women in Spain from different ethnic backgrounds (e.g. from South America) and beliefs of males may be different from the ones held by our sample (Ajzen 2002a). Furthermore, our participants were mainly well-educated women. It is possible that non-participants were less well educated, consequently, salient eating beliefs of women with lower educational backgrounds may have been under-represented. The sample also included very few participants from lower socio-economic backgrounds. Although no differences were detected in the beliefs of lower and higher socio-economic backgrounds in this study low socio-economic status is associated with poor eating behaviours (Hulshof et al. 2003, Shi et al. 2005). These issues form empirical questions to be explored in further research. It is possible that some findings, for instance the importance of the follow-up or health improvements being an important diet outcome, are a result of a social desirability bias (Berg 2001), as interviews took place in a hospital setting and the interviewer was a health professional (Patton 2002). Other researchers in other settings may have obtained different responses from the same participants. Using more than one data collection method, more than one person to collect it and different data sources i.e., interviews with participants' relatives/ friends and records of shopping lists, may have provided different data to triangulate these findings and assess the credibility or validity of data collected and study findings (Berg 2001, Patton 2002).

Participants reported a wide range of beliefs related to eating behaviours. Some can be grouped under what the TPB calls behavioural beliefs (Ajzen 2002a), which designate the benefits of losing weight, as well as the emotions related to dieting. Findings of the present study support results from previous studies that show that behavioural beliefs are associated with attitude (Conner \& Norman 1996a, Gummeson et al. 1997, Armitage \& Conner 1999, Berg et al. 2000). Moreover, as in other studies of eating behaviours, our findings support the new version of TPB (Ajzen 2002a) that proposes that patients' attitudes should be measured, taking into account not only instrumental but also affective beliefs (Lloyd et al. 1993, Berg et al. 2000). The empirical implications of these findings are clear. Interventions aiming to create a more positive attitude towards a diet may be more successful if they reinforce beliefs about health and physical appearance improvements and take into account individual food preferences and tastes, as well as individual's relationship with food when designing a diet. This is an important recommendation as beliefs about taste have been reported to be an important factor in determining attitudes towards different eating behaviours in different populations (Conner \& Norman 1996a, Anderson et al. 1998, Armitage \& Conner 1999, Berg et al. 2000).

Findings also denote several beliefs that correspond with what the TPB calls normative beliefs (Ajzen 2002a). The most important finding regarding normative beliefs is the pressure that participants perceive in the follow-ups, which seems to create in them a subjective norm to maintain the diet. Our findings add evidence to previous research on the TPB which shows that normative beliefs are important components in motivating people to perform specific eating behaviours (Berg et al. 2000, Povey et al. 2001). However, none of the studies reviewed provided evidence on the impact of doctors, nurses or other health professionals on patients following a diet. This would be an interesting area for further research. Beliefs identified in this study support the new version of the TPB as it recommends that normative beliefs should be assessed in terms of injunctive and descriptive norms (Ajzen 2002a).

Participants reported beliefs that fit the TPB's definition of control beliefs (Ajzen 2002a,b). Beliefs about social support seemed to be positively associated with participants' perceived control to follow a diet; whereas beliefs about lack of willpower to overcome temptations and lack of time to cook seemed to decrease their perceived control overeating behaviours. Consequently, dietary interventions with a family approach may be advantageous to help patients to follow a diet. Moreover, as temptations seem to be an important barrier to following a diet (Armitage \& Conner 1999), it may be beneficial to help patients to find ways to recognize and overcome these temptations to increase their perceived control over their eating behaviour. It is also worth mentioning that some participants, especially the one describing herself as an 'emotional eater', may need additional interventions to 
increase skills to manage situations of stress, anxiety or depression that tempt them to eat, with resources other than food, for instance, relaxation, meditation or exercise. Participants' reported beliefs reflecting aspects of controllability and efficacy to follow a diet, which are in line with the latest version of the TPB (Armitage \& Conner 1999, Ajzen 2002b).

Data from this study seem to fit the propositions of the TPB and offer plausible explanations of eating behaviours under a weight-loss treatment. The beliefs identified can be a useful target for eating behaviour change interventions, as modifying those beliefs may result in changes in people's attitude, subjective norms and PBC (Ajzen 1991). The next step is to develop a questionnaire to assess the impact that these determinants have on patients' eating behaviours and finally to develop an intervention to help them to adopt healthier eating behaviours (Ajzen 1991). Nonetheless, as Hardeman et al. (2002) conclude, more research is needed to add evidence to the few studies that explored the effectiveness of the behaviour change interventions developed from the TPB.

\section{Conclusion}

Using a qualitative approach enabled exploration of the cognitions underlying participants' eating behaviours, as well as comparison with the propositions of the TPB. The TPB can be used to understand individuals eating behaviours when following a weight-loss diet.

Our findings are both novel and important, as they represent the first time that TPB has been applied to eating and dieting behaviours in a Spanish context. The findings support Ajzen's (2002a) recommendation that researchers and health professionals should look at different components of attitude, subjective norms and PBC when exploring obese and overweight women's eating behaviours. Further research may need to look at this aspect, as well as differences in beliefs and motivations between non-intenders and intenders to follow a diet and differences between people with different educational and socio-economic backgrounds. In addition, it would be worth exploring in more depth the impact that health professionals have on patients following a diet.

\section{Relevance to practice}

Findings support the use of the TPB by nurses and other health professionals to assess patients' attitudes, beliefs and expectations when following a weight-loss treatment. That assessment would provide insight into what aspects are relevant for individual patients when dieting (i.e., health, physical appearance, follow ups, or temptations) and provide guidance for health professionals on which of these aspects to focus on to help patients change their eating behaviours.

\section{Contributions}

Study design: AB, MA, CT; data collection and analysis: AB, MA, CT and manuscript preparation: AB, MA, CT.

\section{Acknowledgements}

This study was supported by School of Nursing, University of Navarra, Pamplona, Spain. Many thanks to Maribel Saracibar, Navidad Canga and Dr. Salvador and his team; as well as to the women who were interviewed.

\section{References}

Ajzen I (1991) The theory of planned behavior. Organisational Behavior and Human Decision Processes 50, 79-211.

Ajzen I (2002a) Constructing a TPB Questionnaire: Conceptual and Methodological Considerations. Available at: www-unix.oit. umass.edu/ aizen/tpb.html (accessed 01 September 2002).

Ajzen I (2002b) Perceived behavioural control, self-efficacy, locus of control and the theory of planned behaviour. Journal of Applied Social Psychology 32, 665-683.

American Obesity Association (2002) Finally a Cure for Obesity (World Wide Web) Available at: http://obesityusa.org (accessed 19 May 2002).

Anderson AS, Cox DN, McKellar S, Reynolds J, Lean MEJ \& Mela DJ (1998) Take five, a nutrition education intervention to increase fruit and vegetable intakes: impact on attitudes towards dietary change. British Journal of Nutrition 80, 133-140.

Armitage CJ \& Conner M (1999) Distinguishing perceptions of control from self-efficacy: predicting consumption of a low-fat diet using the theory of planned behaviour. Journal of Applied Social Psychology 29, 72-90.

Armitage CJ \& Conner M (2000) Social cognition models and health behaviour: a structured review. Psychology \& Health 15, 173-189.

Armitage CJ \& Conner M (2001) Efficacy of the theory of planned behaviour: a meta-analytic review. British Journal of Social Psychology 40, 471-499.

Berg BL (2001) Qualitative Research Methods for the Social Sciences, 4th edn. Allyn and Bacon, London.

Berg C, Jonsson J \& Conner M (2000) Understanding choice of milk and bread for breakfast among Swedish children aged 11-15 years: an application of the theory of planned behaviour. Appetite 34, 5-19.

Blue CL (1995) The predictive capacity of the theory of reasoned action and the theory of planned behaviour in exercise research: an integrated literature review. Research in Nursing and Health $18,105-121$. 
Centers for Disease Control and Prevention (2006) CDC's Behaviour Risk Factor Surveillance System. Available at: http://www.cdc.gov (accessed 06 November 2006).

Conner M \& Armitage CJ (1998) Extending the theory of planned behaviour: a review and avenues for further research. Journal of Applied Social Psychology 28, 1429-1464.

Conner M \& Norman P (1996a) Body weight and shape control: examining component behaviours. Appetite 27, 135-150.

Conner M \& Norman P (1996b) Predicting Health Behaviour. Open University Press Buckingham, UK.

Conner M \& Norman P (1996c) The role of social cognition in health behaviours. In Predicting Health Behaviour (Conner M \& Norman P eds). Open University Press, Buckingham, pp. 1-22.

Conner M, Norman P \& Bell R (2002) The theory of planned behavior and healthy eating. Health Psychology 21, 194-201.

Department of Health (2005) Health Survey for England 2004. Updating of trend tables to include 2004 data. Available at: http:// www.dh.gov.uk (accessed 06 November 2006).

Glaser BG \& Strauss AL (1968) The Discovery of Grounded Theory: Strategies for Qualitative Research. Weidenfeld and Nicolson, London, UK.

Godin G \& Kok G (1996) The theory of planned behaviour: a review of its applications to health-related behaviors. American Journal of Health Promotion 11, 87-98.

Gummeson L, Jonsson I \& Conner M (1997) Predicting intentions and behaviour of Swedish 10-16 year-olds at breakfast. Food quality and Preferences 8, 297-306.

Hagger MS, Chatzisarantis NLD \& Biddlem SJH (2002) A metaanalytic review of the theories of reasoned action and planned behaviour in physical activity: predictive validity and the contribution of additional variables. Journal of Sport and Exercise Psychology 24, 3-32.

Hardeman W, Johnston M, Johnston D, Bonetti D, Wareham N \& Kinmonth L (2002) Application of the theory of planned behaviour in behaviour change interventions: a systematic review. Psychology and Health 17, 123-158.

Hausenblas HA, Carron AV \& Mack DE (1997) Application of the theories of reasoned action and planned behavior to exercise behavior: a meta-analysis. Journal of Sport and Exercise Psychology 19, 36-51.

Hulshof KF, Brussaard JH, Kruizinga AG, Telman J \& Lowik MR (2003) Socio-economic status, dietary intake and 10 y trends: the Dutch National Food Consumption Survey. European Journal of Clinical Nutrition 57, 128-137.

Lloyd HM, Paisley CM \& Mela DJ (1993) Changing to a low fat diet: attitudes and beliefs of UK consumers. European Journal of Clinical Nutrition 47, 361-373.

Malasu JR \& Astrom AN (2001) Predicting intended and self-perceived sugar restriction among Tanzanian students using the theory of planned behaviour. Journal of Health Psychology 6, 435-445.
Martinez Gonzalez MA (1997) Bioestadistica. Aplicacion e interpretacion en Ciencias de la Salud. Newbook Ediciones, Pamplona, Spain.

Miles MB \& Huberman AM (1994) Qualitative Data Analysis. An Expanded Sourcebook, 2nd edn. SAGE Publications, London, UK.

National Heart Lung and Blood Institute NHLBI (1998) Clinical Guidelines on the Identification, Evaluation and Treatment of Overweight and Obesity in Adults. Available at: http:// www.nhlbi.nih.gov/guidelines/obesity (accessed 28 May 2002).

National Statistics Socioeconomic classification (NS-SEC). Available at: http://www.statistics.gov.uk/methods_quality/ns_sec/default. asp (accessed 07 November 2006).

Neuman WL (2000) Social Research Methods: Qualitative and quantitative approaches, 4th edn. Ally and Bacon, London, UK.

Nguyen MN, Otis J \& Potvin L (1996) Determinants of intention to adopt a low-fat diet in men 30 to 60 years old: implications for heart health promotion. American Journal of Health Promotion 10, 201-207.

Norman P \& Conner N (1996) The role of social cognition models in predicting health behaviours: future directions. In Predicting Health Behaviour (Conner M \& Norman P eds). Open University Press, Buckingham.

Paisley CM \& Sparks S (1998) Expectations of reducing fat intake: the role of perceived need within the theory of planned behavior. Psychology and Health 13, 341-353.

Patton MQ (2002) Qualitative Evaluation and Research Methods, 3rd edn. SAGE Publications, London.

Povey R, Conner M, Sparks P, James R \& Shepherd R (2000) The theory of planned behaviour and healthy eating: examining additive and moderating effects of social influence variables. Psychology and Health 14, 991-1006.

Povey R, Wellens B \& Conner M (2001) Attitudes towards following meat, vegetarian and vegan diets: an examination of the role of ambivalence. Appetite 37, 15-26.

Shi Z, Lien N, Kumar BN \& Holmboe-Ottesen G (2005) Sociodemographic differences in food habits and preferences of school adolescents in Jiangsu Province, China. European Journal of Clinical Nutrition 59, 1439-1448.

Spanish Department of Health (2003) Encuesta Nacional de Salud 2003. Available at: http://www.msc.es/salud. (accessed 03 November 2002).

Sutton S (1998) Predicting and explaining intentions and behavior: how well are we doing? Journal of Applied Social Psychology 28, 1317-1338.

World Health Organization (2002) Nutrition: Controlling the Global Obesity Epidemic. Available at: http://www.who.int/nut/obs.htm (accessed 03 May 2002).

Young HM, Lierman L, Powell-Cope G, Kasprzyk D \& Benoliel JQ (1991) Operationalizing the theory of planned behavior. Research in Nursing and Health 14, 137-144. 